\title{
Adenomyosis: Epidemiology, Risk Factors, Clinical Phenotype and Surgical and Interventional Alternatives to Hysterectomy
}

\author{
Adenomyosis: Epidemiologie, Risikofaktoren, klinisches Erscheinungsbild \\ sowie chirurgische und interventionelle Alternativen zur Hysterektomie
}

Authors

Affiliations

\author{
F. A. $\operatorname{Taran}^{1}$, E. A. Stewart ${ }^{2}$, S. Brucker ${ }^{1}$
}

1 Women's Clinic, University Tübingen, Tübingen, Germany

${ }^{2}$ Department of Obstetrics and Gynecology and Surgery, Mayo Clinic, Rochester, Minnesota, USA

\section{Key words}

- adenomyosis

- hysterectomy

- endometrial ablation

- uterine artery embolization

- magnetic resonance guided focused ultrasound

\section{Schlüsselwörter \\ - Adenomyosis \\ - Hysterektomie \\ - Endometriumsablation \\ - Uterusarterienembolisation \\ - Magnetresonanztomogra- fie-gesteuerte fokussierte Ultraschalltherapie}

received $\quad 14.8 .2013$ revised $\quad 30.8 .2013$ accepted $\quad 30.8 .2013$

Bibliography

DOI http://dx.doi.org/ 10.1055/s-0033-1350840

Geburtsh Frauenheilk 2013; 73: 924-931 @ Georg Thieme

Verlag KG Stuttgart · New York . ISSN 0016-5751

\section{Correspondence}

Dr. Florin Andrei Taran

University Tübingen

Women's Clinic

Calwerstraße 7

72076 Tübingen

florin.andrei.taran@gmail.com

\section{Abstract \\ $\nabla$}

Adenomyosis is an important clinical challenge in gynecology and healthcare economics; in its fully developed form, hysterectomy is often used to treat it in premenopausal and perimenopausal women. Symptoms of adenomyosis typically include menorrhagia, pelvic pain and dysmenorrhea. Moreover, adenomyosis and leiomyomas commonly coexist in the same uterus, and differentiating the symptoms for each pathological process can be problematic. Although it has been recognized for over a century, reliable epidemiological studies on this condition are limited, because only postoperative diagnoses were possible in the past. Minimally invasive surgical techniques (endometrial ablation/resection, myometrial excision/reduction, myometrial electrocoagulation, uterine artery ligation) have had limited success in the treatment of adenomyosis, and the reported data for these procedures have been obtained from case reports or small case series with only short follow-up times. However, newer techniques including uterine artery embolization (UAE) and magnetic resonance imaging guided focused ultrasound (MRgFUS) show promise in treating adenomyosis. The data is strongest for UAE; these studies have the largest patient cohorts. However, none of the UAE studies were randomized or controlled. Thus, despite the clinical importance of adenomyosis, there is little evidence on which to base treatment decisions. The objective of this review is to summarize the epidemiology, risk factors, clinical phenotype and to evaluate the accrued experience with surgical and interventional alternatives to hysterectomy.

\section{Zusammenfassung \\ $\nabla$}

Die Adenomyosis uteri stellt eine große klinische Herausforderung für sowohl Gynäkologie als auch Gesundheitsökonomie dar. Oftmals ist sie bei symptomatischen prä- und perimenopausalen Frauen Indikation zur Hysterektomie. Typische Symptome der Adenomyosis uteri werden mit Menorrhagie, Unterbauchschmerzen und Dysmenorrhö beschrieben. Bei den benignen Erkrankungen des Uterus kommen die Adenomyosis und die Leiomyome häufig gleichzeitig vor und erschweren so eine eindeutige Zuordnung der Symptomatik. Obgleich die Erstbeschreibung der Adenomyosis uteri aus dem letzten Jahrhundert stammt, existieren zu diesem Krankheitsbild nach wie vor keine verlässlichen epidemiologischen Daten. Dies liegt auch in der Tatsache begründet, dass in der Vergangenheit nur eine postoperative Diagnose dieser Erkrankung möglich war. Minimalinvasive chirurgische Therapieansätze (Endometriumablation/-resektion, myometrane Exzision/Reduktion, myometrane Elektrokoagulation, Ligatur der Aa. uterinae) haben nur begrenzte Erfolge in der Behandlung der Adenomyosis uteri zeigen können. Darüber hinaus stammt die Evidenz zu diesen Therapieansätzen ausschließlich aus Studien mit geringen Fallzahlen und Fallberichten. Dennoch zeigen neuere, interventionelle Techniken einschließlich der Uterusarterienembolisation (UAE) und der Magnetresonanztomografie-gesteuerten fokussierten Ultraschalltherapie (MRgFUS) aussichtsreiche Ergebnisse in der uteruserhaltenden Behandlung der Adenomyosis. Obwohl die meisten Ergebnisse diesbezüglich für die UAE vorhanden sind, waren diese Arbeiten weder randomisiert noch kontrolliert. Trotz der großen klinischen Bedeutung der Adenomyosis uteri gibt es nach wie vor keine ausreichende Evidenz für nachhaltige Therapieempfehlungen. Ziel dieser Übersichtsarbeit ist eine Zusammenfassung der epidemiologischen Daten, 
der Risikofaktoren, des klinischen Erscheinungsbilds der Adenomyosis uteri sowie eine Analyse der eigenen Erfahrung mit chirurgischen und interventionellen Therapiemodalitäten in der Behandlung der Adenomyosis.

\section{Introduction}

\section{$\nabla$}

The first description of the condition initially referred to as "adenomyoma" was provided in 1860 by the German pathologist Carl von Rokitansky, who found endometrial glands in the myometrium and subsequently referred to this finding as "cystosarcoma adenoids uterinum" [1,2]. The modern definition of adenomyosis was provided in 1972 by Bird who stated: "Adenomyosis may be defined as the benign invasion of endometrium into the myometrium, producing a diffusely enlarged uterus which microscopically exhibits ectopic non-neoplastic, endometrial glands and stroma surrounded by the hypertrophic and hyperplastic myometrium" [1].

Because of the widespread use of hysterectomy as the primary therapeutic option, starting in the 19th century, adenomyosis has never been fully characterized. Currently the designation of benign uterine diseases including adenomyosis and uterine fibroids resembles the 19th century designation of "cancer" before the importance of histological and molecular factors affecting therapeutic response and prognosis was highlighted.

The development of high-resolution imaging techniques, particularly magnetic resonance (MR) imaging, has improved the preoperative diagnosis of adenomyosis. On T2-weighted MR images of the uterus, the junctional zone myometrium can be clearly distinguished from the endometrium and outer myometrium, and diffuse or focal thickening of this zone is now recognized as one hallmark of adenomyosis [3]. Furthermore, both MR and transvaginal ultrasound (TVU) are valuable in characterizing adenomyosis as they can identify myometrial cysts, distorted and heterogeneous myometrial echotexture and poorly defined foci of abnormal myometrial echotexture. However, the most predictive TVU finding for adenomyosis is the presence of ill-defined myometrial heterogeneity [4]. MR imaging offers sensitivity rates of up to $88 \%$ and specificity rates of up to $93 \%$. Studies comparing MR and TVU offer inconclusive data, with some studies reporting equivalent results, and others report the superiority of MR imaging [5].

Medications such as non-steroidal anti-inflammatory drugs and/ or hormonal therapy (oral contraceptive pills, high-dose progestins, a levonorgestrel-releasing intrauterine device, danazol, gonadotropin-releasing hormone agonists) are often used to manage the symptoms of adenomyosis and to temporarily induce regression of the adenomyosis. However, many women require more aggressive forms of treatment [6].

Historically, the most common treatment for symptomatic adenomyosis has been hysterectomy. Thus, an important factor driving innovation in adenomyosis therapies is perioperative and postoperative morbidity as well as the potentially lower qualityof-life outcome associated with hysterectomy. Moreover, hysterectomy is also not appropriate in women who wish to have children.

A different area driving innovation in adenomyosis therapies is the high healthcare costs. Recent reports have suggested that healthcare costs are higher for women with leiomyomas than for unaffected women, and the costs of disability are substantial, in all probability because surgical therapy in the form of hyster- ectomy procedures is the major treatment option. Hysterectomies account for most of the costs, recently estimated to exceed $\$ 2.1$ billion annually in the United States and almost 200 million $€$ in Germany $[7,8]$. Nevertheless, despite the clinical importance of adenomyosis, there is little evidence on which to base treatment decisions. The objective of this review was to summarize the epidemiology, risk factors, clinical phenotype and to evaluate the accrued experience with surgical and interventional alternatives to hysterectomy.

\section{Epidemiology}

In the past, the diagnosis of adenomyosis was made solely based on histological analysis. An accurate determination of its incidence or prevalence has therefore not been carried out [4]. Thus, estimates of the prevalence of adenomyosis vary widely, from 5 to $70 \%$, with the mean frequency of adenomyosis at hysterectomy given as approximately 20 to 30\% [9-14]. In a large series of consecutive laparoscopic supracervical hysterectomies performed in the Gynecological University Clinic in Tübingen, adenomyosis was diagnosed histologically in $8 \%$ of cases (149 women out of 1955 women), and concomitant adenomyosis and leiomyomas was diagnosed histologically in $20 \%$ of the women (398 women out of 1955 women); $70 \%$ of the women with a diagnosis of adenomyosis were premenopausal [15].

There appear to be wide variations in the incidence of adenomyosis between racial and ethnic groups and different geographic regions [13]. It is not clear whether this is due to patient factors or differences in diagnosis [13]. In addition, with an increasing number of hysterectomies performed as laparoscopic supracervical interventions, resulting consequently in morcellated uterine specimens, the spatial arrangement of the tissue is modified, leading to a different reference to the surface and making the histological diagnosis of adenomyosis more challenging. Finally, the likelihood of establishing the presence of adenomyosis is directly proportional to the number of tissue samples taken, with the diagnosis rate ranging from 31 to $62 \%$ in the same uterus [16].

\section{Risk Factors \\ $\nabla$ \\ Age}

70 to $80 \%$ of women undergoing hysterectomy for adenomyosis are in their fourth and fifth decade of life and are multiparous; several studies have reported a mean age over 50 years for women undergoing hysterectomy for adenomyosis $[4,9,13,14,17-$ 22]. However, newer reports using MRI criteria for diagnosis suggest that the disease may cause dysmenorrhea and chronic pelvic pain in adolescents and women of younger reproductive age than previously appreciated $[23,24]$. These reports suggest that the clinical age at presentation of adenomyosis may be significantly earlier than previously thought and that early-stage adenomyosis might present a different clinical phenotype compared to latestage disease. 


\section{Multiparity}

A high percentage of women with adenomyosis are multiparous $[17-19,25,26]$. Pregnancy might facilitate the formation of adenomyosis by allowing adenomyotic foci to be included in the myometrium due to the invasive nature of the trophoblast on the extension of the myometrial fibers $[25,26]$. In addition, adenomyotic tissue may have a higher ratio of estrogen receptors and the hormonal milieu of pregnancy may favor the development of islands of ectopic endometrium $[4,13]$. Alternatively, there may be an increased acceptance of hysterectomy in multiparous women.

\section{Prior uterine surgery}

Evidence regarding a significantly increased risk of prior uterine surgery in women with adenomyosis is inconsistent. Clinical data have supported the hypothesis that adenomyosis results when endometrial glands invade the myometrial layer, with surgical disruptions of the endometrial-myometrial border increasing the risk of adenomyosis in some studies $[27,28]$.

Levgur et al. and Parazzini et al. reported that patients who had undergone pregnancy termination via dilation and curettage demonstrated higher rates of adenomyosis than women without pregnancy terminations $[14,27]$. Furthermore, Parazzini et al. and Taran et al. also observed higher rates of adenomyosis in non-pregnant patients who had undergone dilation and curettage $[11,17]$. Whitted et al. observed an increased prevalence of adenomyosis in subjects who had had prior cesarean section [29]. However, other studies reported no increased rates of cesarean section or any other uterine surgical procedure in women with adenomyosis $[12,18,19,30]$.

Thus, it is unclear whether a history of previous uterine surgery is a risk factor for adenomyosis [4]. Moreover, positing a relationship between surgical history and the incidence of adenomyosis is risky when considering the selection of surgical patients. The patients included in the overwhelming majority of studies were treated in an era when laparotomy was commonly performed; the results from these studies may well be different if they were conducted today [19].

\section{Smoking}

Evidence regarding an association between smoking and adenomyosis is controversial. On the one hand, in comparison with women who never smoked, smokers appear less likely to have adenomyosis [11]. This finding can be explained by hormonally induced mechanisms: decreased serum levels of estrogen have been reported in smokers, and adenomyosis has been suggested to be an estrogen-dependent disorder [31,32].

Alternatively, there is also evidence that there is no association between adenomyosis and smoking [14]. Moreover, two studies even reported a higher rate of a history of smoking in women with adenomyosis than in controls $[19,33]$. Thus, the association between adenomyosis and smoking deserves further investigation.

\section{Ectopic pregnancy}

Implantation in a focus of adenomyosis could result in a pregnancy developing within the myometrium $[34,35]$. In addition, cigarette smoking has been shown to be an independent, doserelated risk factor for ectopic pregnancy [36]. Thus, it has been hypothesized that women with adenomyosis are more likely to have a history of ectopic pregnancy, since adenomyosis may be a risk factor for the development of intramural ectopic pregnancy
$[19,34,35]$. Another possible explanation for the higher rate of ectopic pregnancies in women with adenomyosis is thus the higher rate of women with a history of smoking [19]. Nevertheless, assumptions regarding an increased likelihood of a history of smoking and ectopic pregnancy in association with adenomyosis are hypotheses that require additional evidence.

\section{Depression and antidepressant use}

Novel associations with adenomyosis found in both human and animal studies include an increased risk of depression, and higher antidepressant use [17,39-41]. This association may be due to abnormalities in prolactin dynamics. Exposure of the murine uterus to increased prolactin appears to be sufficient to cause histological adenomyosis and is associated with up-regulation of the uterine prolactin receptor messenger RNA $[37,38]$.

In vitro studies have demonstrated that prolactin is produced by human uterine tissues including the endometrium, myometrium and leiomyomas and that a functional prolactin receptor is present in the uterus and capable of acting as a smooth muscle cell mitogen $[17,42-44]$. However, in the study by Taran et al., too few of the women with adenomyosis had serum prolactin results to permit direct analysis of this relationship. Furthermore, it is possible that depression may have a common pathogenic factor with adenomyosis (i.e., inflammation) [17]. Studies have showed that the growth and progression of endometriosis and adenomyosis continues even in ovariectomized animals. This indicates that, in addition to ovarian steroid hormones, the growth of endometriosis may be regulated by the innate immune system in the pelvic environment [45].

\section{Tamoxifen treatment}

Adenomyosis is relatively rare in postmenopausal women but a higher incidence of adenomyosis has been reported in women treated with tamoxifen for breast cancer [46-49]. Tamoxifen is an antagonist of the estrogen receptor in breast tissue via its active metabolite, hydroxytamoxifen. In tissues, including the endometrium, it behaves like an agonist, and adenomyosis can develop or be reactivated [50]. Thus, adenomyosis may be more common than is generally realized in women taking tamoxifen and may account for postmenopausal bleeding in these patients [49].

\section{Clinical Phenotype \\ $\nabla$}

Symptoms of adenomyosis typically include menorrhagia, chronic pelvic pain and dysmenorrhea. Until recently, the diagnosis of adenomyosis was rarely established prior to hysterectomy and therefore, it is unsurprising that preoperative diagnosis rates of adenomyosis based on clinical findings are poor, ranging from 3 to $26 \%$ [13]. The presenting symptoms of adenomyosis are nonspecific and can also be observed for disorders such as dysfunctional uterine bleeding, leiomyomas and endometriosis, among others. Thus, certain findings on the relationship between adenomyosis, menorrhagia, dysmenorrhea and pelvic pain are controversial $[12,13]$.

Owolabi and Strickler stated in 1977 that "the common association of adenomyosis with more obvious pelvic disease has diminished its significance as a cause of gynaecologic symptoms. Adenomyosis is the addendum to textbook chapters on ectopic endometrium; it is the forgotten process and a neglected diagnosis" [51]. Weiss et al. concluded more than three decades later that 
"adenomyosis is an incidental finding and not the source of symptomatology for women that undergo hysterectomy" [26]. However, most of the data that led to these conclusions was from retrospective studies and, in the case of the Weiss study, from studies of women late in the perimenopausal transition when symptoms are likely to be on the wane. In contrast to leiomyomas, no published and validated symptom questionnaire specific to adenomyosis is available.

Adenomyosis and leiomyomas commonly coexist in the same uterus. The incidence of concomitant adenomyosis in hysterectomy specimens of women with leiomyomas is reported to range between 15 and $57 \%$ [10,11,14,26,52,53]. Thus, differentiating the symptoms for each pathological process can be problematic. Furthermore, the accurate preoperative differentiation of both conditions in the same uterus remains poor, even with the addition of imaging techniques including ultrasound and magnetic resonance imaging [6].

However, recent studies suggest that there are ways in which women undergoing hysterectomy with adenomyosis differ from women who have only leiomyomas. Women with adenomyosis have been shown to have lower uterine weights, more dysmenorrhea, dyspareunia, pelvic pain and more disease-specific symptoms compared to women with leiomyomas alone $[18,19]$.

Furthermore, a number of features have been outlined that distinguish women with adenomyosis and leiomyomas from women with only leiomyomas at the time of hysterectomy. Women with adenomyosis and leiomyomas reported more dysmenorrhea and had an increased risk of dyspareunia and pelvic pain compared to women with leiomyomas alone [18]. The finding that women with adenomyosis and leiomyomas undergoing hysterectomy have fewer and smaller leiomyomas suggests that adenomyosis may contribute to or synergize with leiomyomas to increase symptomatology, which in turn will be treated by hysterectomy [18]. Consequently, in women with symptoms that seem disproportionate to the level of leiomyoma disease, clinicians should consider the presence of adenomyosis in the differential diagnosis [18].

Major limitations of these studies included their retrospective design which precluded an objective measurement of symptom severity. Furthermore, racial diversity was underrepresented in all studies. While the incidence and prevalence of leiomyomas in black women has been shown to be increased and the disease more severe, there is no data on racial differences for adenomyosis $[54,55]$.

\section{Surgical and Interventional Alternatives to Hysterectomy $\nabla$}

\section{Hysteroscopic procedures}

\section{Endometrial ablation/resection}

Hysteroscopy has become a major diagnostic and therapeutic tool for uterine disorders [56]. Hysteroscopic endometrial ablation/resection has been used to treat patients with menorrhagia, including patients with adenomyosis. Endometrial ablation/resection can be performed using an yttrium aluminum garnet (YAG) laser, rollerball resection, or global ablation techniques (thermal balloon ablation, cryoablation, circulated hot fluid ablation, microwave ablation, and bipolar radiofrequency ablation). Levgur summarized the experience with more than 2000 patients treated by YAG laser for abnormal bleeding in his recent review [56]. All analyzed publications underlined the risk of failure in patients with adenomyosis and in several cases, particularly if foci penetration exceeded $2.5 \mathrm{~mm}$, hysterectomy was considered to be unavoidable [56]. Wallwiener et al. performed endometrial ablation combining YAG laser and an electrosurgical loop in a series of 34 symptomatic, "high-risk" patients with contraindications for hysterectomy [57]. Endometrial ablation was successful in 28 of 34 cases; in this series of patients, hysterectomy, with the risk of major or even lethal complications, could thus be avoided. However hysterectomy had to be performed in 2 women with extensive adenomyosis [57].

Wood et al. analyzed the therapeutic efficacy of endometrial resection in a series of 22 patients [58,59]. In this series, a marked improvement occurred in 4 of 7 patients with adenomyosis after endometrial resection [58]. In the second series, endometrial resection cured menorrhagia in 12 of 15 patients but dysmenorrhea in only 3 of 8 [59]. However, endometrial resection reduced the need for hysterectomy to $30 \%$ in this group of patients [59]. Hysteroscopic ablation by rollerball was first described in 1989 using a modified urological resectoscope [60]. The initial case series included 15 patients treated for dysfunctional uterine bleeding [60]. After at least 6 months of follow-up, 10 patients had amenorrhea or hypomenorrhea. There was one failure; the patient underwent vaginal hysterectomy 4 months after the procedure and was found to have adenomyosis [60]. This pattern of failure for rollerball ablation for patients with adenomyosis has been confirmed in several studies [61,62].

A large retrospective cohort study from the Mayo Clinic, Rochester, MN, USA, analyzed the long-term outcomes and predictors of outcome for women undergoing global endometrial ablation (either thermal balloon ablation or radiofrequency ablation) to treat menorrhagia [63]. Univariate analysis (HR 1.5) showed that women with a diagnosis of adenomyosis on ultrasound who underwent global endometrial ablation had an increased risk of failure and required subsequent hysterectomy or repeat ablation. However, adenomyosis was not identified as an independent predictor of treatment failure in the final multivariable model [63].

\section{Excisional procedures \\ Myometrial/adenoymoma excision \\ and myometrial reduction}

Focal excision of adenomyosis can be performed if the location of foci can be determined. However, unlike myomectomy, it is difficult to expose the lesions, define margins and determine the extent of disease and thus, the efficacy of excision remains low at $50 \%$ [4]. Myometrial reduction to treat symptomatic adenomyosis refers to the removal of diseased tissue from the uterus. A large proportion of the myometrium is removed and the created wedge defect is repaired by metroplasty. The procedure can be performed by laparoscopy, mini-laparotomy or laparotomy [56, 64]. A classic incision is made, with dissection of the uterus longitudinally in the midline and resection of the anterior and posterior portions of the myometrium [4].

Fedele et al. evaluated reproductive performance after adenomyoma excision in a prospective, observational study of 28 women who wished to maintain fertility [65]. Thirteen (72.2\%) women conceived; however, seven women (38.8\%) had spontaneous abortions. The cumulative pregnancy rate at 36 months of follow-up was $74.7 \%$ with a total of 18 pregnancies, of which nine (50\%) ended in term deliveries [65]. The high rate of spontaneous abortions in this study is likely due to the large excisions needed which could have reduced the gestational capability of uterus or 
due to residual adenomyomatous growths that could have interfered with the course of pregnancy [65].

The largest study on adenomyomectomy to date included 165 women treated with surgery alone or with combined surgicalmedical treatment (surgery followed by six months' administration of a gonadotropin-releasing hormone agonist) [66]. Adenomyomectomy was performed by mini-laparotomy, ultraminilaparotomy, or laparoscopy. Women in both groups experienced statistically significant symptom relief, and all symptom scores declined from a mean at the end of the 2-year follow-up period; the symptom-recurrence rates in the surgical-medical group were statistically significantly lower than those in the surgeryalone group [66]. Additionally, fifty-five women became pregnant, with a clinical pregnancy rate of $77.5 \%$, and 49 women (69.0\%) had a successful delivery [66].

Fujishita et al. reported a modified method of reduction surgery of lesions in a small series of women with imaging diagnosis of adenomyosis [67]. A transverse $\mathrm{H}$-incision method for reduction surgery was used in 6 women, and conventional reduction surgery was performed in 5 women with adenomyosis. The subjective relief of pain was more evident in the $\mathrm{H}$-incision group. There was no case of pregnancy in the conventional surgery group; however, 1 patient conceived spontaneously 4 months after surgery using the H-incision approach [67].

Osada et al. reported a new method of adenomyomectomy, whereby adenomyotic tissues were excised and the uterine wall was reconstructed using a triple-flap method [68]. The reported procedure resulted in a reduction in symptoms and a low recurrence rate and allowed over half of the women who wished to conceive to carry their pregnancy to term without uterine rupture [68].

\section{Other surgical procedures}

Uterine artery ligation

Only one study investigated the effect of laparoscopic uterine artery ligation in 20 women with symptomatic adenomyosis [69]. Both uterine arteries were laparoscopically ligated with hemoclips, and electrocoagulation of both uterine ovarian vessels was performed. Six months postoperatively, mean uterine volume had decreased between 0.4 and $74.0 \%$. Two of nine women achieved remission of the mass effect of an enlarged uterus. Thirteen of 16 patients achieved bleeding control and 5 reported eumenorrhea or hypomenorrhea. Twelve of 16 patients achieved control of dysmenorrhea and 6 were analgesia-free. However, nine women experienced non-menstrual pain after surgery, three of whom later underwent hysterectomy. Treatment outcome was rated as satisfactory by only $15 \%$ of patients, and $45 \%$ were dissatisfied. Seventeen women would have refused the procedure if they could make the decision again. The authors concluded that the poor satisfaction rate suggests that symptomatic adenomyosis may not be effectively treated by laparoscopic uterine artery ligation [69].

\section{Myometrial electrocoagulation}

Electrocoagulation has the capacity to shrink adenomyosis by causing necrosis. The technique can be carried out laparoscopically to treat localized or extensive disease [70]. Myometrial electrocoagulation of adenomyosis is a laparoscopic procedure that can be carried out using unipolar or bipolar needles and a coagulation current of 50 watts. However, the procedure is considered to be less accurate than surgical excision because electri-
Table 1 Studies on the outcome of uterine artery embolization in the treatment of adenomyosis.

\begin{tabular}{|c|c|c|c|}
\hline Study, year [reference] & $\begin{array}{l}\text { Patients } \\
\text { (n) }\end{array}$ & $\begin{array}{l}\text { Symptoms } \\
\text { improved } \\
n(\%)\end{array}$ & $\begin{array}{l}\text { Follow-up } \\
\text { (months) }\end{array}$ \\
\hline Goodwin et al., 1999 [72] & 6 & $3(50)$ & 10.2 \\
\hline Siskin et al., 2001 [74] & 13 & $12(92)$ & 8.2 \\
\hline Jha et al., 2003 [75] & 9 & $9(100)$ & 12.0 \\
\hline Toh et al., 2003 [76] & 12 & $3(25)$ & 10.9 \\
\hline Kim et al., 2004 [77] & 43 & $40(93)$ & 3.5 \\
\hline Pelage et al., 2005 [78] & 9 & $5(55)$ & 24.0 \\
\hline Kitamura et al., 2006 [79] & 11 & $10(91)$ & 12.0 \\
\hline Kim et al., 2007 [80] & 54 & $31(57)$ & 58.8 \\
\hline Bratby and Walker, 2009 [81] & $\begin{array}{l}16^{1} \\
11^{2}\end{array}$ & $\begin{array}{c}13(79)^{1} ; \\
6(56)^{2}\end{array}$ & 36.0 \\
\hline Liang et al., 2012 [82] & 17 & $17(100)$ & 6.0 \\
\hline Smeets et al., 2012 [83] & 40 & $29(73)$ & 65.0 \\
\hline
\end{tabular}

at 12 months follow-up; ${ }^{2}$ at 36 months follow-up

cal conduction in abnormal tissue may be incomplete and this cannot be evaluated during surgery [70].

\section{Other interventions}

Uterine artery embolization

Uterine artery embolization (UAE) for women with symptomatic leiomyomas was first reported in 1995 [71]. UAE is a minimally invasive procedure and represents an alternative to surgery. UAE has been reported to be effective in women with leiomyomas and is associated with high patient satisfaction rates [5]. Additionally, UAE is more cost-effective and has shorter recovery periods and less pain compared to surgical techniques [5]. Commonly reported side effects of UAE are pelvic pain, nausea and fever due to ischemic necrosis [6]. In addition, approximately $5 \%$ of patients experience major complications including hemorrhage, unplanned surgical procedures and infection. Moreover, there are reports of an age-related impairment of ovarian function following UAE [6].

Adenomyosis and leiomyomas often coexist in the same uterus and their symptoms are often similar. Thus, performing UAE in women with leioymomas will also include patients with adenomyosis [6]. At the outset of UAE for women with symptomatic leiomyomas, several authors attributed unsatisfactory clinical results to the presence of concurrent adenomyosis $[72,73]$. These observations reinforced the importance of a correct diagnosis before UAE and the need to evaluate a possible negative impact of adenomyosis on the clinical outcome of UAE [6].

There are, however, a number of encouraging reports in the last 14 years on the use of UAE for the treatment of adenomyosis (O Table 1). Kim et al. reported the largest study of patients who underwent UAE for adenomyosis without leiomyomas; the study included 54 patients with a follow-up period of at least 3 years [80]. Thirty-one (57.4\%) of the 54 women who were followed up demonstrated long-term success; 4 patients had immediate failure of treatment, and 19 patients had recurrence. Changes in menorrhagia and dysmenorrhea scores at follow-up showed a significant relief of symptoms [80]. The time between UAE and the recurrence of symptoms ranged from 4 to 48 months (mean, 17.3 months). Five patients underwent hysterectomy because of symptom recurrence. Mean reduction in volume of the uterus was $26.3 \%$ at short-term follow-up and $27.4 \%$ at long-term follow-up [80]. Thus, the study by Kim et al. was the first to show 
that UAE has an acceptable long-term success rate in the management of symptomatic adenomyosis.

Bratby and Walker analyzed 27 women with symptomatic adenomyosis diagnosed on MRI who underwent UAE [81]. There was an initial favorable clinical response, with improvement of menorrhagia in 79\% (13/16) of patients at 12 months. Follow-up data was available for a total of 14 patients at 2 and 3 years after embolization; $45.5 \%$ reported a deterioration in menorrhagia symptoms at 3 years. The authors concluded that UAE for symptomatic adenomyosis is effective in the short-term but there is a high recurrence rate of clinical symptoms 2 years following treatment [81].

The study with the longest follow-up (mean clinical follow-up: 65 months) evaluated UAE in 40 consecutive women with adenomyosis, of whom 22 women had a concomitant diagnosis of leiomyomas [83]. Changes in junction zone thickness were assessed with magnetic resonance imaging (MRI) at baseline and again at 3 months. During follow-up, 7 of 40 women (18\%) underwent hysterectomy; of the 33 women with preserved uterus, 29 were asymptomatic [83]. There was no association between clinical outcome and the initial presence of leiomyomas in addition to adenomyosis. Furthermore, UAE resulted in long-term preservation of the uterus in the majority of patients and the only predictor for hysterectomy during follow-up was the initial thickness of the junction zone [83].

Several studies conducted on the efficacy of UAE in symptomatic adenomyosis have shown sustained clinical and symptomatic improvements. However, none of the studies were controlled or randomized. Thus, the efficacy of UAE in adenomyosis remains unclear, primarily because of a lack of high-quality data [84]. Larger-scale, randomized controlled studies with longer followup times are mandatory to determine the efficacy of UAE in the treatment of adenomyosis.

\section{Magnetic resonance-guided focused ultrasound}

Magnetic resonance-guided focused ultrasound (MRgFUS) surgery was approved by the United States Food and Drug Administration (FDA) as a noninvasive treatment for uterine leiomyomas [85]. Focused ultrasound surgery delivers a concentrated quantity of ultrasound energy to deep tissue areas without thermal effects to surrounding tissue [86].

The underlying process in adenomyosis is smooth muscle hyperplasia and thus, MRgFUS treatment is ideal to target such lesions [86]. The distinction between leiomyomas and adenomyosis is made using MR imaging to show diffuse or focal thickening of the junctional zone of the uterus in the presence of adenomyosis [86].

Initial experience with MRgFUS to treat symptomatic adenomyosis has shown promising results [87-90]. The first patient treated with MRgFUS for symptomatic adenomyosis completed the treatment with no complications, had improvement of menorrhagia and shrinkage of the adenomyomatous mass [87]. The patient conceived spontaneously after the procedure, and pregnancy and delivery were not affected by MRgFUS treatment [87]. Fukunishi et al. reported early results that indicated the safe and effective ablation of adenomyosis tissue by MRgFUS. The procedure also resulted in an improvement of clinical symptoms during the 6 months of follow-up [89].

Kim et al. evaluated the degree of symptom relief obtained after treatment with MRgFUS in patients with adenomyosis [91]. Quality-of-life and pain assessment questionnaires from 35 women, collected on the day of treatment and up to 6 months after treatment, indicated that the treatment was safe and that there was a significant reduction in symptoms [91]. Nevertheless, although these reports show encouraging results for the use of MRgfUS to treat adenomyosis, additional studies into the safety and efficacy of MRgFUS for women with adenomyosis are necessary.

\section{Conclusions \\ $\nabla$}

Adenomyosis is an important clinical challenge in gynecology and healthcare economics; in its fully developed form hysterectomy is often used to treat it in pre-menopausal and perimenopausal women. Although it has been recognized for over a century, reliable epidemiological studies on this condition are limited, probably because in the past diagnosis was only possible postoperatively [13]. Symptomatic women receiving treatment for adenomyosis are mostly in their fourth or fifth decade and multiparous. However, the diagnosis is increasingly being made in younger women who wish to maintain their fertility. Thus, the evolution of minimally invasive and uterine-conserving therapies and the demand for these therapies requires a better understanding of the disease. Additionally, there are no evidence-based guidelines to treat adenomyosis using minimally invasive methods [6].

Minimally invasive surgical interventions (endometrial ablation/ resection, myometrial excision/reduction, myometrial electrocoagulation, uterine artery ligation) were primarily introduced to treat symptomatic women with adenomyosis but have had limited success in the treatment of adenomyosis. Moreover, all reported data are from case reports or small case series with short follow-up times. Thus, although some studies have reported follow-up data including pregnancy and delivery rates, these procedures are not generally recommended for women who wish to maintain fertility.

On the other hand, uterine artery embolization and magnetic resonance imaging guided focused ultrasound therapy have shown encouraging results in the treatment of adenomyosis. The studies on uterine artery embolization showed the most promising results and were carried out in the largest patient cohorts. However, none of the UAE studies were randomized or controlled. Thus, the efficacy of UAE in adenomyosis remains unclear, primarily because of a lack of high-quality data. Furthermore, at present the American College of Obstetrics and Gynecology and the Society of Interventional Radiology list the desire for future fertility as a relative contraindication to UAE [92]. In spite of all these shortcomings, the emergence of various surgical and interventional therapeutic modalities for a condition that, for decades, could only be solved by hysterectomy is most gratifying [52].

The ontogeny of adenomyosis is clearly important for the development of new alternatives to hysterectomy. Prospective randomized and controlled studies with larger cohorts, validated and disease-specific symptom questionnaires, noninvasive diagnostic modalities as well as new surgical and interventional alternatives to hysterectomy are required to better understand adenomyosis and to avoid hysterectomy.

For some women with adenomyosis who have completed their family planning, hysterectomy still remains the best option. Understanding the diversity of the disease, both with regards to pathology and symptomatology, will lead to targeted therapies in the short term and prevention strategies in the longer term. Our 
goal as researchers of benign myometrial lesions is to understand the biology of these lesions and provide evidence to guide individualized treatment (surgery vs. lifestyle modification vs. novel therapies based on research insights) in the future.

\section{Conflict of Interest}

$\nabla$

None.

\section{References}

1 Benagiano G, Brosens I. History of adenomyosis. Best Pract Res Clin Obstet Gynaecol 2006; 20: 449-463

2 Renner SP, Lermann J, Hackl J et al. Chronische Erkrankung. Endometriose. Geburtsh Frauenheilk 2012; 72: 914-919

3 Gordts S, Brosens JJ, Fusi L et al. Uterine adenomyosis: a need for uniform terminology and consensus classification. Reprod Biomed Online 2008; 17: 244-248

4 Garcia L, Isaacson K. Adenomyosis: review of the literature. J Minim Invasive Gynecol 2011; 18: 428-437

5 Popovic M, Puchner S, Berzaczy D et al. Uterine artery embolization for the treatment of adenomyosis: a review. J Vasc Interv Radiol 2011; 22: 901-909

6 Rabinovici J, Stewart EA. New interventional techniques for adenomyosis. Best Pract Res Clin Obstet Gynaecol 2006; 20: 617-636

7 Fernandez H, Farrugia M, Jones SE et al. Rate, type, and cost of invasive interventions for uterine myomas in Germany, France, and England. J Minim Invasive Gynecol 2009; 16: 40-46

8 Cardozo ER, Clark AD, Banks NK et al. The estimated annual cost of uterine leiomyomata in the United States. Am J Obstet Gynecol 2012; 20 : 211.e1-211.e9

9 Azziz R. Adenomyosis: current perspectives. Obstet Gynecol Clin North Am 1989; 16: 221-235

10 Vercellini P, Parazzini F, Oldani S et al. Adenomyosis at hysterectomy: a study on frequency distribution and patient characteristics. Hum Reprod 1995; 10: 1160-1162

11 Parazzini FVP, Panazza S, Chatenoud L et al. Risk factors for adenomyosis. Hum Reprod 1997;12: 1275-1279

12 Bergholt T, Eriksen L, Berendt $N$ et al. Prevalence and risk factors of adenomyosis at hysterectomy. Hum Reprod 2001; 16: 2418-2421

13 Vercellini P, Vigano P, Somigliana E et al. Adenomyosis: epidemiological factors. Best Pract Res Clin Obstet Gynaecol 2006; 20: 465-477

14 Parazzini F, Mais V, Cipriani $S$ et al. Determinants of adenomyosis in women who underwent hysterectomy for benign gynecological conditions: results from a prospective multicentric study in Italy. Eur J Obstet Gynecol Reprod Biol 2009; 143: 103-106

15 Wallwiener M, Taran FA, Rothmund R et al. Laparoscopic supracervical hysterectomy (LSH) versus total laparoscopic hysterectomy (TLH): an implementation study in 1,952 patients with an analysis of risk factors for conversion to laparotomy and complications, and of procedurespecific re-operations. Arch Gynecol Obstet 2013; Jun 18 [Epub ahead of print]

16 Bird CC, McElin T, Manalo-Estrella P. The elusive adenomyosis of the uterus. Am J Obstet Gynecol 1972; 112: 583-593

17 Taran FA, Weaver AL, Coddington CC et al. Understanding adenomyosis: a case control study. Fertil Steril 2010; 94: 1223-1228

18 Taran FA, Weaver AL, Coddington CC et al. Characteristics indicating adenomyosis coexisting with leiomyomas: a case-control study. Hum Reprod 2010; 25 : 1177-1182

19 Taran FA, Wallwiener M, Kabashi D et al. Clinical characteristics indicating adenomyosis at the time of hysterectomy: a retrospective study in 291 patients. Arch Gynecol Obstet 2012; 285: 1571-1576

20 Siedentopf $P$. Chronic pain syndromes in gynaecological practice: endometriosis and fibromyalgia. Geburtsh Frauenheilk 2012; 72: 10921098

21 Burghaus S, Klingsiek P, Fasching PA et al. Risk factors for endometriosis in a German case-control study. Geburtsh Frauenheilk 2011; 71: 1073-1079

22 Wölfler MM, Stadermann M, Rath W et al. Anamnestisches Screening bei symptomatischen Patientinnen mit und ohne Endometriose. Geburtsh Frauenheilk 2011; 71: 53-58
23 Parker JD, Leondires M, Sinaii N et al. Persistence of dysmenorrhea and nonmenstrual pain after optimal endometriosis surgery may indicate adenomyosis. Fertil Steril 2006; 86: 711-715

24 Ryan GL, Stolpen A, Van Voorhis BJ. An unusual cause of adolescent dysmenorrhea. Obstet Gynecol 2006; 108: 1017-1022

25 Templeman C, Marshall SF, Ursin G et al. Adenomyosis and endometriosis in the California Teachers Study. Fertil Steril 2008; 90: 415-424

26 Weiss G, Maseelall P, Schott $L L$ et al. Adenomyosis a variant, not a disease? Evidence from hysterectomized menopausal women in the Study of Women's Health Across the Nation (SWAN). Fertil Steril 2009; 91: 201-206

27 Levgur M, Abadi MA, Tucker A. Adenomyosis: symptoms, histology, and pregnancy terminations. Obstet Gynecol 2000; 95: 688-691

28 Panganamamula UR, Harmanli OH, Isik-Akbay EF et al. Is prior uterine surgery a risk factor for adenomyosis? Obstet Gynecol 2004; 104: 1034-1038

29 Whitted R, Verma U, Voigl B et al. Does cesarean delivery increase the prevalence of adenomyosis? A retrospective review. Obstet Gynecol 2000; 95: S83

30 Harris WJ, Daniell JF, Baxter JW. Prior cesarean section. A risk factor for adenomyosis? J Reprod Med 1985; 30: 173-175

31 Van Voorhis BJ, Dawson JD, Stovall DW et al. The effects of smoking on ovarian function and fertility during assisted reproduction cycles. Obstet Gynecol 1996; 88: 785-791

32 Kitawaki J. Adenomyosis: the pathophysiology of an oestrogen-dependent disease. Best Pract Res Clin Obstet Gynaecol 2006; 20: 493-502

33 Yeniel O, Cirpan T, Ulukus $M$ et al. Adenomyosis: prevalence, risk factors, symptoms and clinical findings. Clin Exp Obstet Gynecol 2007; 34: $163-167$

$34 \mathrm{Lu} \mathrm{HF}$, Sheu BC, Shih JC et al. Intramural ectopic pregnancy. Sonographic picture and its relation with adenomyosis. Acta Obstet Gynecol Scand 1997; 76: 886-889

35 Ginsburg KA, Quereshi F, Thomas M et al. Intramural ectopic pregnancy implanting in adenomyosis. Fertil Steril 1989; 51: 354-356

36 Saraiya M, Berg CJ, Kendrick JS et al. Cigarette smoking as a risk factor for ectopic pregnancy. Am J Obstet Gynecol 1998; 178: 493-498

37 Mori T, Singtripop T, Kawashima S. Animal model of uterine adenomyosis: Is prolactin a potent inducer of adenomyosis in mice? Am J Obstet Gynecol 1991; 165: 232-234

38 Yamashita M, Matsuda M, Mori T. In situ detection of prolactin receptor mRNA and apoptotic cell death in mouse uterine tissues with adenomyosis. In Vivo 1999; 13: 57-60

39 Ficicioglu C, Tekin HI, Arioglu PF et al. A murine model of adenomyosis: the effects of hyperprolactinemia induced by fluoxetine hydrochloride, a selective serotonin reuptake inhibitor, on adenomyosis induction in Wistar albino rats. Acta Eur Fertil 1995; 26: 75-79

40 Molitch ME. Medication-induced hyperprolactinemia. Mayo Clin Proc 2005; 80: 1050-1057

41 Greaves P, White IN. Experimental adenomyosis. Best Pract Res Clin Obstet Gynaecol 2006; 20: 503-510

42 Walters CA, Daly DC, Chapitis J et al. Human myometrium: a new potential source of prolactin. Am J Obstet Gynecol 1983; 147: 639-644

43 Daly DC, Walters CA, Prior JC et al. Prolactin production from proliferative phase leiomyoma. Am J Obstet Gynecol 1984; 148: 1059-1063

44 Mora S, Diehl T, Stewart EA et al. Prolactin is an autocrine growth regulator for human myometrial and leyomyoma cells. J Soc Gynecol Invest 1995; 2: 396

45 Khan KN, Kitajima M, Fujishita A et al. Toll-like receptor system and endometriosis. J Obstet Gynaecol Res 2013; 39: 1281-1292

46 Cohen I, Beyth Y, Tepper R et al. Adenomyosis in postmenopausal breast cancer patients treated with tamoxifen: a new entity? Gynecol Oncol 1995; 58: 86-91

47 Cohen I, Beyth Y, Shapira J et al. High frequency of adenomyosis in postmenopausal breast cancer patients treated with tamoxifen. Gynecol Obstet Invest 1997; 44: 200-205

48 Cohen I, Shapira J, Beyth Yet al. Estrogen and progesterone receptors of adenomyosis in postmenopausal breast cancer patients treated with tamoxifen. Gynecol Obstet Invest 1998; 45: 126-131

49 McCluggage WG, Desai V, Manek S. Tamoxifen-associated postmenopausal adenomyosis exhibits stromal fibrosis, glandular dilatation and epithelial metaplasias. Histopathology 2000; 37: 340-346

50 Deligdisch $L$. Effects of hormone therapy on the endometrium. Mod Pathol 1993; 6: 94-106

51 Owolabi TO, Strickler RC. Adenomyosis: a neglected diagnosis. Obstet Gynecol 1977; 50: 424-427 
52 Shaikh H, Khan KS. Adenomyosis in Pakistani women: four year experience at the Aga Khan University Medical Centre, Karachi. J Clin Pathol 1990; 43: 817-819

53 Vavilis D, Agorastos T, Tzafetas J et al. Adenomyosis at hysterectomy: prevalence and relationship to operative findings and reproductive and menstrual factors. Clin Exp Obstet Gynecol 1997; 24: 36-38

54 Thomas jr. JS, Clark JF. Adenomyosis: a retrospective view. J Natl Med Assoc 1989; 81: 969-972

55 Peddada SD, Laughlin SK, Miner K et al. Growth of uterine leiomyomata among premenopausal black and white women. Proc Natl Acad Sci U S A 2008; 105: 19887-19892

56 Levgur M. Therapeutic options for adenomyosis: a review. Arch Gynecol Obstet 2007; 276: 1-15

57 Wallwiener D, Rimbach S, Kaufmann M et al. Hysteroscopic endometrial ablation to avoid hysterectomy in high-risk patients. Geburtsh Frauenheilk 1994; 54: 498-501

58 Wood C, Maher P, Hill D. Biopsy diagnosis and conservative surgical treatment of adenomyosis. Aust N Z J Obstet Gynaecol 1993; 33: 319321

59 Wood C, Maher P, Hill D. Biopsy diagnosis and conservative surgical treatment of adenomyosis. J Am Assoc Gynecol Laparosc 1994; 1: 313-316

60 Vancaillie TG. Electrocoagulation of the endometrium with the ballend resectoscope. Obstet Gynecol 1989; 74: 425-427

61 Daniell JF, Kurtz BR, Ke RW. Hysteroscopic endometrial ablation using the rollerball electrode. Obstet Gynecol 1992; 80: 329-332

62 Unger JB, Meeks GR. Hysterectomy after endometrial ablation. Am J Obstet Gynecol 1996; 175: 1432-1436

63 El-Nashar SA, Hopkins MR, Creedon DJ et al. Prediction of treatment outcomes after global endometrial ablation. Obstet Gynecol 2009; 113: 97-106

64 Pepas L, Deguara C, Davis C. Update on the surgical management of adenomyosis. Curr Opin Obstet Gynecol 2012; 24: 259-264

65 Fedele L, Bianchi S, Zanotti F et al. Fertility after conservative surgery for adenomyomas. Hum Reprod 1993; 8: 1708-1710

66 Wang PH, Liu WM, Fuh JL et al. Comparison of surgery alone and combined surgical-medical treatment in the management of symptomatic uterine adenomyoma. Fertil Steril 2009; 92: 876-885

67 Fujishita A, Masuzaki H, Khan KN et al. Modified reduction surgery for adenomyosis. A preliminary report of the transverse $\mathrm{H}$ incision technique. Gynecol Obstet Invest 2004; 57: 132-138

68 Osada H, Silber S, Kakinuma T et al. Surgical procedure to conserve the uterus for future pregnancy in patients suffering from massive adenomyosis. Reprod Biomed Online 2011; 22: 94-99

69 Wang $C$, Yen $C F$, Lee $C L$ et al. Laparoscopic uterine artery ligation for treatment of symptomatic adenomyosis. J Am Assoc Gynecol Laparosc 2002; 9: 293-296

70 Wood C. Adenomyosis: difficult to diagnose, and difficult to treat. Diagn Ther Endosc 2001; 7: 89-95

71 Ravina JH, Herbreteau D, Ciraru-Vigneron $N$ et al. Arterial embolisation to treat uterine myomata. Lancet 1995; 346: 671-672

72 Goodwin SC, McLucas B, Lee $M$ et al. Uterine artery embolization for the treatment of uterine leiomyomata midterm results. J Vasc Interv Radiol 1999; 10: 1159-1165

73 Smith SJ, Sewall LE, Handelsman A. A clinical failure of uterine fibroid embolization due to adenomyosis. J Vasc Interv Radiol 1999; 10: $1171-1174$
74 Siskin GP, Tublin ME, Stainken BF et al. Uterine artery embolization for the treatment of adenomyosis: clinical response and evaluation with MR imaging. AJR Am J Roentgenol 2001; 177: 297-302

75 Jha RC, Takahama J, Imaoka I et al. Adenomyosis: MRI of the uterus treated with uterine artery embolization. AJR Am J Roentgenol 2003; 181: 851-856

$76 \mathrm{Toh} \mathrm{CH}, \mathrm{Wu} \mathrm{CH}$, Tsay PK et al. Uterine artery embolization for symptomatic uterine leiomyoma and adenomyosis. J Formos Med Assoc 2003; 102: 701-706

77 Kim MD, Won JW, Lee DY et al. Uterine artery embolization for adenomyosis without fibroids. Clin Radiol 2004; 59: 520-526

78 Pelage JP, Jacob D, Fazel A et al. Midterm results of uterine artery embolization for symptomatic adenomyosis: initial experience. Radiology 2005; 234: 948-953

79 Kitamura Y, Allison SJ, Jha RC et al. MRI of adenomyosis: changes with uterine artery embolization. AJR Am J Roentgenol 2006; 186: 855-864

$80 \mathrm{Kim}$ MD, Kim S, Kim NK et al. Long-term results of uterine artery embolization for symptomatic adenomyosis. AJR Am J Roentgenol 2007; 188: 176-181

81 Bratby MJ, Walker WJ. Uterine artery embolisation for symptomatic adenomyosis-mid-term results. Eur J Radiol 2009; 70: 128-132

82 Liang E, Brown B, Kirsop R et al. Efficacy of uterine artery embolisation for treatment of symptomatic fibroids and adenomyosis - an interim report on an Australian experience. Aust N Z J Obstet Gynaecol 2012; 52: $106-112$

83 Smeets AJ, Nijenhuis RJ, Boekkooi PF et al. Long-term follow-up of uterine artery embolization for symptomatic adenomyosis. Cardiovasc Intervent Radiol 2012; 35: 815-819

$84 \mathrm{Yu}$ L, Wu T, Spain J et al. Uterine artery embolization for the treatment of adenomyosis: questions for long-term efficacy. J Vasc Interv Radiol 2012; 23: 430-432

85 Taran FA, Tempany CM, Regan L et al. Magnetic resonance-guided focused ultrasound (MRgFUS) compared with abdominal hysterectomy for treatment of uterine leiomyomas. Ultrasound Obstet Gynecol 2009; 34: 572-578

86 Al Hilli MM, Stewart EA. Magnetic resonance-guided focused ultrasound surgery. Semin Reprod Med 2010; 28: 242-249

87 Rabinovici J, Inbar Y, Eylon SC et al. Pregnancy and live birth after focused ultrasound surgery for symptomatic focal adenomyosis: a case report. Hum Reprod 2006; 21: 1255-1259

88 Yoon SW, Kim KA, Cha SH et al. Successful use of magnetic resonanceguided focused ultrasound surgery to relieve symptoms in a patient with symptomatic focal adenomyosis. Fertil Steril 2008; 90: 2018. e13-2018.e15

89 Fukunishi H, Funaki K, Sawada $\mathrm{K}$ et al. Early results of magnetic resonance-guided focused ultrasound surgery of adenomyosis: analysis of 20 cases. J Minim Invasive Gynecol 2008; 15: 571-579

90 Polina L, Nyapathy V, Mishra A et al. Noninvasive treatment of focal adenomyosis with MR-guided focused ultrasound in two patients. Indian J Radiol Imaging 2012; 22: 93-97

$91 \mathrm{Kim}$ KA, Yoon SW, Lee C et al. Short-term results of magnetic resonance imaging-guided focused ultrasound surgery for patients with adenomyosis: symptomatic relief and pain reduction. Fertil Steril 2011; 95: 1152-1155

92 Mohan PP, Hamblin MH, Vogelzang RL. Uterine artery embolization and its effect on fertility. J Vasc Interv Radiol 2013; 24: 925-930 